\title{
An elaboration of the I.L.O. classification of simple pneumoconiosis
}

\author{
F. D. K. LIDDELL AND D. C. LINDARS ${ }^{1}$ \\ The National Coal Board
}

Liddell, F. D. K., and Lindars, D. C. (1969). Brit. J. industr. Med., 26, 89-100. An elaboration of the I.L.O. classification of simple pneumoconiosis. Simple pneumoconiosis in chest radiographs presents a continuum of increasing abnormality. Liddell (1963) introduced a 12-point scale obtained by dividing each of the four I.L.O. categories (International Labour Office, 1959) into one central and two marginal zones. In this system, which has come to be known as the N.C.B. elaboration, readers record for each radiograph the I.L.O. category of choice $(0,1,2$ or 3$)$, followed by an adjacent I.L.O. category if that had been seriously considered; otherwise, the same category is repeated. Very clear normals are denoted as $0 /-$, and 'high' category 3 films as $3 / 4$.

This paper reviews the evidence from seven reading trials in which 12 National Coal Board (N.C.B.) film readers have taken part. About 28,000 assessments on a total of well over 2,000 single radiographs have been analysed. (The reading of serial radiographs to assess progression is dealt with elsewhere.)

All readers used the elaboration successfully, but they differed in the extents to which they placed films in central and in marginal zones; they were more consistent when preliminary briefing had been given. Film quality had little influence on the use of the zones, except that $0 /-$ tended to be reserved for films of good quality.

Despite the variation in the use of the zones, marked improvements accrued from the use of the elaboration in both intra- and inter-observer error for all readers, and for films of poor quality as well as for good films. The validity of expressing simple pneumoconiosis prevalence rates in terms of I.L.O. categories derived from N.C.B. elaboration readings was confirmed. Although the exact widths of the zones along the continuum remain to be determined, all the evidence suggests that they represent steadily increasing abnormality.

Thus, the N.C.B. elaboration is a practical procedure which amplifies, but neither distorts nor supplants, the I.L.O. classification. It is reported to be easier to use.

The reading of a chest radiograph for simple pneumoconiosis (small opacities) ${ }^{2}$ is an attempt to evaluate the number and size of opacities in the lung fields, caused by the disease. The international classification (I.L.O., 1959) allows for the recording both of quantitative features (in four categories,

1Present address: Pneumoconiosis Medical Panel, 92/98 Queen Street, Sheffield, S1 1WU.

${ }^{2}$ No account is taken in this paper of large opacities (Progressive Massive Fibrosis-P.M.F.).
$0,1,2$, and 3 , depending on the extent and profusion of the opacities) and of qualitative features (in three types; punctiform, micro-nodular, and nodular, defined according to the greatest diameter of the predominant opacities). Most British work on the classification has concentrated on the quantitative aspect, probably largely because of the major additional difficulty (as pointed out by Blair $e t$ al., 1966), in deciding visually which type of opacity is predominant in mixed radiographs. This paper is 
therefore concerned with the quantitative features of classification. In order to simplify presentation, a standard terminology has been introduced; it is given in Appendix I (p. 98), which also includes an explanation of the abbreviations used.

Any classification of pneumoconiosis, to be useful, must be sensitive enough to distinguish between the normal and the abnormal, and to determine when a change of severity of the condition has taken place in a particular subject. It is axiomatic that the higher the sensitivity achieved the better. Clearly, too, a high degree of consistency is desirable so that one reader on different occasions, or different readers, should be able to place a film in a similar position on the continuum of abnormality.

However, these two aims are - as in all diagnostic procedures - conflicting. The fewer the classes which the procedure attempts to differentiate, the higher the possible degree of repeatability, but of course the lower the sensitivity. In the extreme, perfect repeatability could be achieved by the use of a classification which was wholly insensitive, but this is clearly to reduce the procedure to absurdity. Conversely, where measurements can be made on a scale on which a large number of steps, each of equal importance, can be differentiated, it becomes possible to achieve any degree of sensitivity and consistency required, provided sufficient effort can be expended.

The N.C.B. elaboration was introduced in an attempt to improve sensitivity. In effect, it subdivides each I.L.O. category into three, by means of the following instructions:

Please record the (I.L.O.) category into which you would classify the film following the normal convention. If, in the course of that classification, you considered an adjacent category as a serious possibility, please record that category [after an oblique stroke]; otherwise, please repeat the I.L.O. category [after a stroke].

'Barn-door' normals, i.e., films over which you have no trace of doubt that they are normal, should be recorded as 0/-. If a film shows evidence of so much dust retention that you consider there can be no doubt it would always be read as category 3 , enter $3 / 4$.

The elaboration is illustrated in the Figure. The symbols differ from the notation used in the original experiment (Liddell, 1963), but this is the only material change.
The results of that experiment were encouraging. Thus, when account was taken of the extent of disagreements, both intra-observer and interobserver error were found to be considerably reduced. Further, there were indications that the additional information might be of considerable importance in assessing the progression of pneumoconiosis in groups of subjects. However, this work had, of course, been of an exploratory nature; in particular, it had been carried out by only three experienced film readers and had been based on only a small number of films which had been drawn from a colliery with both high dust exposures and a high prevalence of pneumoconiosis. Generalization was necessary, as was the examination of other possible defects, if the worth of the elaboration was not to remain in doubt.

First, the elaboration introduced zones which are in effect sub-categories with boundaries that are not strictly defined. Indeed, the definitions are mainly in terms of whether or not an adjacent I.L.O. category was 'seriously considered'. It was possible that the degree of indecision, and hence the position of boundaries, would depend both on the reader and on the radiographic technique of the films; the inexperienced reader might perhaps be less decisive, while the poorer films, being more difficult to read, might also lead to more indecision.

Secondly, the interpretation, in terms of I.L.O. categories, of readings which had been made into the elaboration required study.

Thirdly, there was the possibility that reading standards had changed after many months of use of the elaboration.

Fourthly, although it had been commented that the effort of reading was reduced by use of the elaboration, the possibility that this was due to over-ready employment of alternates rather than making difficult decisions on categorization needed investigation.

Finally, it was possible that the differences between the zones within each I.L.O. category did not correspond to real differences in lung pathology.

This paper presents evidence from a number of film-reading trials in an attempt to find answers to the following questions:

(1) Do individual readers place similar proportions of films in the various zones, despite undoubtedly nebulous definitions?

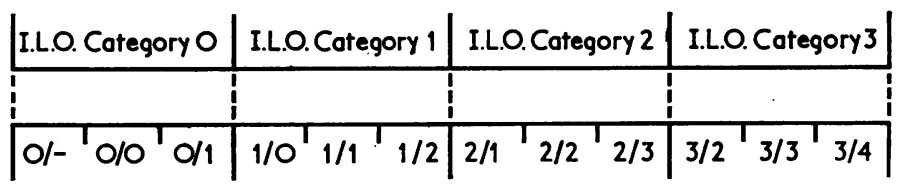

FIGURE. The N.C.B. elaboration of the I.L.O. classification. 
(2) Does poor radiographic technique lead to more indecision, i.e., greater use of the marginal zones?

(3) Can I.L.O. categories be validly obtained by ignoring the alternates recorded in the elaboration?

(4) Does a group of readers maintain consistent reading levels when using the elaboration over many months?

(5) Does the elaboration lead to improved observer error on all series of films?

(6) If so, are the improvements affected by radiographic technique?

(7) Are all the zones of the continuum meaningful? For example, should $0 /-$ and $0 / 0$ be distinguished? And are the differences between adjacent marginal zones (e.g., between $0 / 1$ and $1 / 0$, or between $2 / 3$ and $3 / 2$ ) real?

The trials are discussed very briefly below, and more fully in Appendix II (p. 98). A discussion of the evidence follows its presentation; it should be appreciated that the trials were carried out over a period of years during development of techniques, and so differences would not be unexpected as experience was gained. The use of information theory to assess observer error is described in Appendix III (p. 99).

\section{Data}

The data on which this paper is based came from seven film-reading trials. Trials 1,2 , and 3 were annual checks on the consistency of film reading in the course of the Periodic $X$-ray Scheme (P.X.R.). They were all concerned with single films taken in the ordinary course of P.X.R. routine, spread over the 10 mobile $x$-ray units and over time. All the P.X.R. readers in post at the time of the check took part. In each of these trials, some films were included which had been incorporated into the preceding check of consistency, thus allowing temporal comparison over a number of years. The I.L.O. classification was used throughout trial 1 and the N.C.B. elaboration throughout trial 3. In the meantime, trial 2 had been specially adapted to examine some of the questions listed above; the design was complex, as can be seen from Appendix II.

The remaining trials formed parts of investigations in connexion with methods of assessing the radiological progression of simple pneumoconiosis. Serial films were available from two (or in one case, three) medical surveys carried out by the Pneumoconiosis Field Research (P.F.R.) at intervals of roughtly five years. However, one of the methods being examined was 'independent randomized' reading, in which all films were arranged in a single quasi-random series, care having been taken to ensure that the films for a particular subject were well separated from each other. Thus the films can be treated for the purpose of this report as a single random series of independent films. ${ }^{1}$ Details of these investigations, insofar as they provide evidence on the use of the N.C.B. elaboration in reading single films, are given in Appendix II. For the purposes of the analyses, the few cases showing large opacities (P.M.F.) have been excluded.

\section{The evidence}

Use made of marginal zones by individual readers This can be assessed from all trials in which the N.C.B. elaboration was used. It is dealt with here in terms of the results in trials $2,5,6$, and 7 , i.e., the

${ }^{1}$ It is also possible to study the random series formed of either the 'old' or the 'new' films; the conclusions reported in this paper were completely confirmed by such studies, but only those based on the larger number of films are reported here.

TABLE 1

Use of Zones of the Elaboration: Numbers of Films PlaCed in EACH Zone, eXCluding Readings of Progressive Massive Fibrosis

Trial 2. Seven P.X.R. readers

\begin{tabular}{|c|c|c|c|c|c|c|c|c|c|c|c|c|c|}
\hline \multirow{2}{*}{ Reader } & \multicolumn{3}{|c|}{ Category 0} & \multicolumn{3}{|c|}{ Category 1} & \multicolumn{3}{|c|}{ Category 2} & \multicolumn{3}{|c|}{ Category 3} & \multirow{2}{*}{ Total } \\
\hline & $0 /-$ & $0 / 0$ & $0 / 1$ & $1 / 0$ & $1 / 1$ & $1 / 2$ & $2 / 1$ & $2 / 2$ & $2 / 3$ & $3 / 2$ & $3 / 3$ & $3 / 4$ & \\
\hline $\begin{array}{l}\text { X.1 } \\
\text { X.2 } \\
\text { X.3 } \\
\text { X.4 } \\
\text { Y.2 } \\
\text { Y.3 } \\
\text { Y.4 }\end{array}$ & $\begin{array}{l}13 \\
20 \\
23 \\
24 \\
- \\
-31\end{array}$ & $\begin{array}{l}30 \\
34 \\
62 \\
54 \\
90 \\
78 \\
57\end{array}$ & $\begin{array}{r}24 \\
21 \\
6 \\
12 \\
6 \\
22\end{array}$ & $\begin{array}{r}15 \\
8 \\
4 \\
10 \\
2 \\
7 \\
6\end{array}$ & $\begin{array}{r}11 \\
5 \\
10 \\
3 \\
16 \\
7 \\
1\end{array}$ & $\begin{array}{r}7 \\
12 \\
5 \\
5 \\
4 \\
5\end{array}$ & $\begin{array}{r}9 \\
10 \\
4 \\
10 \\
4 \\
12 \\
2\end{array}$ & $\begin{array}{r}16 \\
8 \\
4 \\
10 \\
19 \\
13 \\
8\end{array}$ & $\begin{array}{r}2 \\
3 \\
3 \\
4 \\
-\end{array}$ & $\begin{array}{r}2 \\
3 \\
1 \\
- \\
5 \\
1\end{array}$ & $\begin{array}{r}2 \\
5 \\
5 \\
1 \\
3 \\
2 \\
-\end{array}$ & $\begin{array}{r}3 \\
4 \\
4 \\
1 \\
- \\
-\end{array}$ & $\begin{array}{l}134 \\
133 \\
131 \\
134 \\
134 \\
134 \\
134\end{array}$ \\
\hline All & 111 & 405 & 91 & 52 & 53 & 38 & 51 & 78 & 13 & 12 & 18 & 12 & 934 \\
\hline
\end{tabular}


first and latest occasions on which the elaboration was used by the P.X.R. and P.F.R. film readers.

Table 1 gives, for each reader in trial 2, the number of films placed in each zone on the first block of films read in this way. It is clear that readers Y.2 and Y.3 differed markedly from the others by placing many fewer films in the marginal zones than in the central zones. In fact, neither of these readers used the zones $0 /-$ or $3 / 4$; reader $Y .2$ placed all but six of his films in the central zones.

Table 2(a), derived from Table 1, provides data for the other five readers. It will be seen that they placed approximately half the films into marginal and half into the central zones; the proportions were encouragingly consistent from reader to reader (varying from $38 \%$ to $61 \%$ in the marginal zones) and also from category to category ( $45 \%$ to $72 \%)$, when it is borne in mind that this was the first time that any of the readers concerned had read the elaboration formally.

In fact, for this trial, no advice on the instructions had been given and no discussion had taken place beforehand; the films had been circulated to the seven radiological centres in the coalfields and were read locally. For trial 4, therefore, the readers were briefed in the hope that inter alia greater consistency would be obtained. This hope was in fact achieved: the findings for all seven P.X.R. readers were similar to those in Table 2.

\section{TABLE 2}

Use of Marginal and Central Zones BY P.X.R. Readers: Percentages of Readings In MARGINAL AND Central ZoNes Trials 2 and 5. Five P.X.R. readers

\begin{tabular}{|c|c|c|c|c|c|}
\hline \multicolumn{3}{|c|}{$\begin{array}{l}\text { Reader by reader } \\
\text { (all categories) }\end{array}$} & \multicolumn{3}{|c|}{$\begin{array}{c}\text { Category by category } \\
\text { (all readers) }\end{array}$} \\
\hline Reader & $\begin{array}{c}\text { Marginal } \\
\text { zones } \\
(\%)\end{array}$ & $\mid \begin{array}{c}\text { Central } \\
\text { zones } \\
(\%)\end{array}$ & Category & $\begin{array}{c}\text { Marginal } \\
\text { zones } \\
(\%)\end{array}$ & $\begin{array}{c}\text { Central } \\
\text { zones } \\
(\%)\end{array}$ \\
\hline $\begin{array}{c}\text { (a) First oc } \\
\text { X.1 } \\
\text { X.2 } \\
\text { X.3 } \\
\text { X.4 } \\
\text { Y.4 }\end{array}$ & \begin{tabular}{|c|} 
casion (tria \\
56 \\
61 \\
38 \\
49 \\
51
\end{tabular} & $\begin{array}{l}\text { 2) } \\
44 \\
39 \\
62 \\
51 \\
49\end{array}$ & $\begin{array}{l}0 \\
1 \\
2 \\
3\end{array}$ & $\begin{array}{l}45 \\
72 \\
51 \\
59\end{array}$ & $\begin{array}{l}55 \\
28 \\
49 \\
41\end{array}$ \\
\hline Average & 51 & 49 & Average & 51 & 49 \\
\hline $\begin{array}{l}\text { (b) Latest } \\
\text { X.1 } \\
\text { X.2 } \\
\text { X.3 } \\
\text { X.4 } \\
\text { Y.4 }\end{array}$ & \begin{tabular}{|c|} 
ccasion (tri \\
46 \\
44 \\
35 \\
42 \\
41
\end{tabular} & \begin{tabular}{|l} 
al 5) \\
54 \\
56 \\
65 \\
58 \\
59
\end{tabular} & $\begin{array}{l}0 \\
1 \\
2 \\
3\end{array}$ & $\begin{array}{l}35 \\
60 \\
40 \\
40\end{array}$ & $\begin{array}{l}65 \\
40 \\
60 \\
60\end{array}$ \\
\hline Average & 42 & 58 & Average & 42 & 58 \\
\hline
\end{tabular}

TABLE 3

Use of Marginal and Central Zones BY P.F.R. Readers: Percentages of Readings in Marginal and Central Zones Trials 6 and 7. Four P.F.R. readers

\begin{tabular}{|c|c|c|c|c|c|}
\hline \multicolumn{3}{|c|}{$\begin{array}{l}\text { Reader by reader } \\
\text { (all categories) }\end{array}$} & \multicolumn{3}{|c|}{$\begin{array}{c}\text { Category by category } \\
\text { (all readers) }\end{array}$} \\
\hline Reader & $\begin{array}{c}\text { Marginal } \\
\text { zones } \\
(\%)\end{array}$ & $\begin{array}{c}\text { Central } \\
\text { zones } \\
(\%)\end{array}$ & Category & $\begin{array}{c}\text { Marginal } \\
\text { zones } \\
(\%)\end{array}$ & $\begin{array}{c}\text { Central } \\
\text { zones } \\
(\%)\end{array}$ \\
\hline $\begin{array}{l}\text { (a) First } \\
\text { F.1 } \\
\text { F.2 } \\
\text { F.3 } \\
\text { F.4 }\end{array}$ & $\begin{array}{c}\text { sion (tria } \\
44 \\
42 \\
48 \\
59\end{array}$ & $\begin{array}{l}\text { l6) } \\
56 \\
58 \\
52 \\
41\end{array}$ & $\begin{array}{l}0 \\
1 \\
2 \\
3\end{array}$ & $\begin{array}{l}49 \\
49 \\
43 \\
57\end{array}$ & $\begin{array}{l}51 \\
51 \\
57 \\
43\end{array}$ \\
\hline Average & 49 & 51 & Average & 49 & 51 \\
\hline $\begin{array}{l}\text { (b) Latest } \\
\text { F.1 } \\
\text { F.2 } \\
\text { F.3 } \\
\text { F.4 }\end{array}$ & $\begin{array}{c}\text { casion (tr } \\
63 \\
18 \\
34 \\
43\end{array}$ & $\begin{array}{l}\text { ial 7) } \\
\begin{array}{l}37 \\
82 \\
66 \\
57\end{array}\end{array}$ & $\begin{array}{l}0 \\
1 \\
2 \\
3\end{array}$ & $\begin{array}{l}38 \\
40 \\
42 \\
44\end{array}$ & $\begin{array}{l}62 \\
60 \\
58 \\
56\end{array}$ \\
\hline Average & 40 & 60 & Average & 40 & 60 \\
\hline
\end{tabular}

Table 2(b) gives similar information for trial 5 , the latest for which data are available. The readers concerned here were a little more consistent in their use of marginal and central zones (35\% to $46 \%$ in the marginal zones). There was, however, a general tendency to place a considerably higher proportion of the films with I.L.O. category 0 into the central zone $(65 \%$ in $0 / 0)$ than into the marginal zones $(35 \%$ in $0 /-$ and $0 / 1)$. This tendency did appear in Table 2(a) but was less marked.

Table 3(a) gives corresponding information for the first trial in which P.F.R. readers used the elaboration formally. The four readers were reasonably consistent in the proportions of films placed in the marginal zone ( $42 \%$ to $59 \%$ ); the proportions were also consistent from category to category $(43 \%$ to $57 \%$ ).

On the only other occasion when the P.F.R. readers read single films into the elaboration (trial 7) the variation between readers $(18 \%$ to $63 \%)$ in their use of marginal zones was very much greater (Table 3(b) ). Once more, there was a tendency on average to use the $0 / 0$ zone in preference to $0 /-$ and $0 / 1$, but it was not at all consistent from reader to reader.

Influence of radiographic technique particularly in relation to use of marginal zones This problem has been examined in detail on only one occasion (trial 2). In this trial, each reader had assessed each film for radiographic quality, scoring $-1,0$ or +1 
TABLE 4

Film QUALITY AND THE USE OF MARGINAL AND Central Zones of I.L.O. Categories 1 and 2: Percentages of Readings of 'Good' and 'BAD' Films In MARgINAL AND CenTral ZONES

Trial 2. Five P.X.R. readers

\begin{tabular}{c|c|c||c|c}
\hline \multirow{2}{*}{ Reader } & \multicolumn{2}{|c||}{ 'Good' films } & \multicolumn{2}{c}{ 'Bad' films } \\
\cline { 2 - 5 } & $\begin{array}{c}\text { Marginal } \\
\text { zones } \\
(\%)\end{array}$ & $\begin{array}{c}\text { Central } \\
\text { zones } \\
(\%)\end{array}$ & $\begin{array}{c}\text { Marginal } \\
\text { zones } \\
(\%)\end{array}$ & $\begin{array}{c}\text { Central } \\
\text { zones } \\
(\%)\end{array}$ \\
\hline X.1 & 47 & 53 & 59 & 41 \\
X.2 & 83 & 17 & 68 & 32 \\
X.3 & 57 & 43 & 52 & 48 \\
X.4 & 46 & 54 & 79 & 21 \\
Y.4 & 33 & 67 & 71 & 29 \\
\hline Average & 54 & 46 & 65 & 35 \\
\hline
\end{tabular}

for a poor, acceptable or particularly good film. A quality score was obtained ${ }^{1}$ for each film by adding together the seven individual assessments and, for the purpose of the present analyses, a film was classified as 'good' if the quality score was 0 or better, and as 'bad' if the score was -1 or worse.

In Table 4 we give, for the five readers involved in Table 2 (i.e., in a majority who made consistent use of the marginal zones), the numbers of readings of the marginal and central zones of I.L.O. categories 1 and $2 .^{2}$ It can be seen that, over all five readers, there was a slight tendency towards greater use of marginal zones on 'bad' films than on 'good'. But this tendency was not statistically significant

1 Justification was given on an earlier occasion by Liddell (1961).

${ }^{2}$ There were too few films in I.L.O. category 3 to justify study.

\section{TABLE 5}

FilM QUALITY AND READING WITHIN I.L.O.

Category 0: Percentages of Readings of

'GOOD' AND ‘BAD' FILMS IN THE ZONES OF CATEGORY 0:

Trial 2. Seven P.X.R. readers

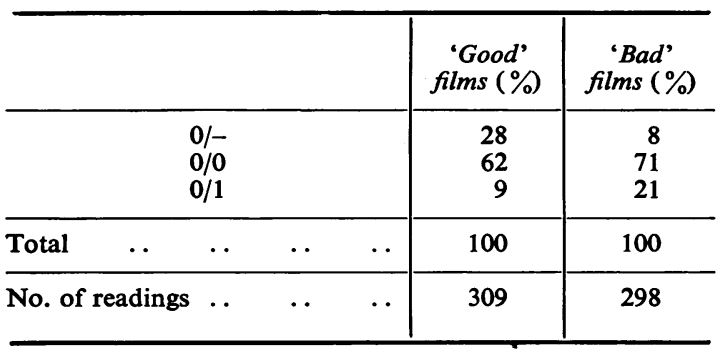

$\left(\chi_{1}^{2}=2 \cdot 06 ; P=15 \%\right):$ indeed the tendency was by no means consistent from reader to reader, and there was little indication of statistical significance for individual readers.

Within I.L.O. category 0 , however, the situation is rather different, as the results in Table 5 for all readers show. Of 'good' films (as compared with 'bad' films) a much higher proportion was classified as $0 /-$ and only about half as many as $0 / 1$. This effect was diluted by readers Y.2 and Y.3 but was common to all the other readers.

Validity of expressing prevalence of pneumoconiosis in terms of I.L.O. categories derived from N.C.B. elaboration readings (by ignoring the alternates) One object in the drafting of the instructions for use of the elaboration was that readings in the elaboration could be interpreted in terms of the standard I.L.O. categories. There is no way of assessing the validity of this procedure directly: we cannot determine how a reader would classify a series of films in any particular circumstances, and we know that he will classify them differently (to some extent) on any two occasions. We can therefore consider the problem only by seeing whether the extent of any one reader's disagreements when reading the same series of films on two occasions (intra-observer error) is similar when he takes part in a three-part trial in which he used: part 1, the I.L.O. classification on both occasions; part 2, the I.L.O. classification and the N.C.B. elaboration on the two occasions; and part 3, the N.C.B. elaboration on both occasions, and in which the readings from parts 2 and 3 are examined without regard to the alternates recorded. Such arrangements were built into trial 2, and the results are summarized in Table 6 (see Appendix III for notes on information transmitted).

\section{TABLE 6}

EFFECT OF IGNORING Alternates: AMOUNTS OF INFORMATION TRANSMITTED INTRA-OBSERVER

Trial 2. Seven P.X.R. readers

\begin{tabular}{|c|c|c|}
\hline $\begin{array}{l}1 \\
2 \\
3\end{array}$ & $\begin{array}{l}\text { I.L.O. classification on both occasions } \\
\text { I.L.O. classification on one occasion; } \\
\text { N.C.B. elaboration }{ }^{1} \text { on the other occasion } \\
\text { N.C.B. elaboration }{ }^{1} \text { on both occasions }\end{array}$ & $\begin{array}{l}1.01 \\
1.05 \\
1.05\end{array}$ \\
\hline
\end{tabular}

${ }^{1}$ Where reading was into the N.C.B. elaboration, the alternates have nevertheless been ignored in this table.

The average amount of information transmitted, averaged over all readers, was almost identical for each part. Further, there was a lack of any consistent 
TABLE 7

GROUPING UP OF READINGS IN THE ELABORATION:

Percentage of Films Placed in I.L.O. Categories, ${ }^{1}$ AND 'Average' Category ${ }^{2}$

Trials 5 and 6. Five P.X.R. readers and four P.F.R. readers

\begin{tabular}{|c|c|c|c|c|c|c|c|c|c|c|c|c|}
\hline \multirow{3}{*}{ Reader } & \multicolumn{6}{|c|}{ I.L.O. classification unelaborated } & \multicolumn{6}{|c|}{ N.C.B. elaboration ${ }^{1}$} \\
\hline & \multicolumn{6}{|c|}{ Category } & \multicolumn{6}{|c|}{ Category } \\
\hline & 0 & 1 & 2 & 3 & All & Average & 0 & 1 & 2 & 3 & All & Average ${ }^{2}$ \\
\hline $\begin{array}{c}\text { (a) P.X.R. rea } \\
\text { X.1 } \\
\text { X.2 } \\
\text { X.3 } \\
\text { X.4 } \\
\text { Y.4 }\end{array}$ & $\begin{array}{l}\text { ial 5) } \\
52 \\
71 \\
48 \\
53 \\
60\end{array}$ & $\begin{array}{l}24 \\
15 \\
24 \\
22 \\
24\end{array}$ & $\begin{array}{r}19 \\
9 \\
21 \\
22 \\
13\end{array}$ & $\begin{array}{l}4 \\
5 \\
6 \\
3 \\
3\end{array}$ & $\begin{array}{l}100 \\
100 \\
100 \\
100 \\
100\end{array}$ & $\begin{array}{l}0.76 \\
0.47 \\
0.85 \\
0.75 \\
0.58\end{array}$ & $\begin{array}{l}52 \\
55 \\
56 \\
51 \\
62\end{array}$ & $\begin{array}{l}23 \\
20 \\
22 \\
25 \\
24\end{array}$ & $\begin{array}{l}22 \\
19 \\
16 \\
20 \\
11\end{array}$ & $\begin{array}{l}3 \\
6 \\
6 \\
3 \\
3\end{array}$ & $\begin{array}{l}100 \\
100 \\
100 \\
100 \\
100\end{array}$ & $\begin{array}{l}0 \cdot 76 \\
0 \cdot 75 \\
0 \cdot 72 \\
0.76 \\
0.55\end{array}$ \\
\hline Average & 57 & 22 & 17 & 4 & 100 & 0.68 & 55 & 23 & 18 & 4 & 100 & $0 \cdot 71$ \\
\hline $\begin{array}{c}\text { (b) P.F.R. rea } \\
\text { F.1 } \\
\text { F.2 } \\
\text { F.3 } \\
\text { F.4 }\end{array}$ & $\begin{array}{c}\text { al } 6) \\
54 \\
70 \\
52 \\
65\end{array}$ & $\begin{array}{l}25 \\
21 \\
23 \\
20\end{array}$ & $\begin{array}{r}14 \\
8 \\
17 \\
10\end{array}$ & $\begin{array}{l}7 \\
1 \\
8 \\
5\end{array}$ & $\begin{array}{l}100 \\
100 \\
100 \\
100\end{array}$ & $\begin{array}{l}0.75 \\
0 \cdot 40 \\
0 \cdot 82 \\
0.55\end{array}$ & $\begin{array}{l}54 \\
71 \\
57 \\
63\end{array}$ & $\begin{array}{l}22 \\
18 \\
23 \\
22\end{array}$ & $\begin{array}{r}16 \\
9 \\
14 \\
9\end{array}$ & $\begin{array}{l}8 \\
2 \\
7 \\
5\end{array}$ & $\begin{array}{l}100 \\
100 \\
100 \\
100\end{array}$ & $\begin{array}{l}0.78 \\
0.42 \\
0.70 \\
0.57\end{array}$ \\
\hline Average & 60 & 22 & 12 & 5 & 100 & 0.63 & 61 & 21 & 12 & 6 & 100 & 0.62 \\
\hline
\end{tabular}

${ }^{1}$ Where reading was into the N.C.B. elaboration, the alternates have been ignored in this table.

'The 'average' category is obtained by treating each reading of $0,1,2$, or 3 as on a cardinal scale.

TABLE 8

VARIATION IN READING LEVELS:

Percentages of Films placed in I.L.O. Categories', and 'Average' Category ${ }^{2}$

Trials 1, 2, and 3. P.X.R. readers

\begin{tabular}{|c|c|c|c|c|c|c|c|c|c|c|}
\hline & & & & & \multicolumn{6}{|c|}{ Category } \\
\hline & & & & & 0 & 1 & 2 & 3 & All & 'Average'? \\
\hline $\begin{array}{l}46 \text { flms }^{3} \text { read on both second and third checks } \\
\text { Second check (a) } \\
\text { [Readers X.1, X.2, X.3, X.4, Y.1, Y.2, Y.3] } \\
\text { Third check (a) } \\
\text { [Readers X.1, X.2, X.3, X.4, Y.1, Y.2, Y.3] }\end{array}$ & $\begin{array}{l}\cdots \\
\ldots\end{array}$ & $\begin{array}{l}\cdots \\
\cdots\end{array}$ & $\begin{array}{l}\cdots \\
\ldots\end{array}$ & $\begin{array}{l}\cdots \\
\cdots\end{array}$ & $\begin{array}{l}9 \\
9\end{array}$ & $\begin{array}{l}41 \\
46\end{array}$ & $\begin{array}{l}35 \\
30\end{array}$ & $\begin{array}{l}15 \\
15\end{array}$ & $\begin{array}{l}100 \\
100\end{array}$ & $\begin{array}{l}1.57 \\
1.52\end{array}$ \\
\hline $\begin{array}{l}49 \text { flms }^{3} \text { read on both third and fourth checks } \\
\text { Third check (a) } \\
\text { [Readers X.1, X.2, X.3, X.4, Y.1, Y.2, Y.3] } \\
\text { Fourth check (b) } \\
\text { [Readers X.1, X.2, X.3, X.4, Y.2, Y.3, Y.4] }\end{array}$ & $\begin{array}{l}\cdots \\
\cdots\end{array}$ & $\begin{array}{l}\cdots \\
\cdots\end{array}$ & $\begin{array}{l}\cdots \\
\cdots\end{array}$ & $\begin{array}{l}\cdots \\
.\end{array}$ & $\begin{array}{l}43 \\
39\end{array}$ & $\begin{array}{l}16 \\
20\end{array}$ & $\begin{array}{l}24 \\
24\end{array}$ & $\begin{array}{l}16 \\
16\end{array}$ & $\begin{array}{l}100 \\
100\end{array}$ & $\begin{array}{l}1 \cdot 14 \\
1 \cdot 18\end{array}$ \\
\hline $\begin{array}{l}63 \text { films }^{3} \text { read on both fourth and fifth checks } \\
\text { Fourth check (b) } \\
\text { [Readers X.1, X.2, X.3, X.4, Y.2, Y.3, Y.4] } \\
\text { Fifth check (c) } \\
\text { [Readers X.1, X.2, X.3, X.4, Y.3, Y.4] }\end{array}$ & $\begin{array}{l}\cdots \\
\ldots\end{array}$ & $\begin{array}{l}\cdots \\
\cdots\end{array}$ & $\begin{array}{l}. . \\
\cdots \\
.\end{array}$ & $\begin{array}{l}\cdots \\
\ldots\end{array}$ & $\begin{array}{l}52 \\
51\end{array}$ & $\begin{array}{l}19 \\
16\end{array}$ & $\begin{array}{l}24 \\
27\end{array}$ & $\begin{array}{l}5 \\
6\end{array}$ & $\begin{array}{l}100 \\
100\end{array}$ & $\begin{array}{l}0.81 \\
0.89\end{array}$ \\
\hline
\end{tabular}

${ }^{1}$ Where reading was into the N.C.B. elaboration [see notes (a), (b) and (c)], the alternate categories have been ignored in this Table.

${ }^{2}$ The 'average' category is obtained by treating each reading of $0,1,2$ or 3 as on a cardinal scale.

${ }^{3}$ All films read on both checks, where P.M.F. was not diagnosed.

(a) Reading into the I.L.O. classification, unelaborated.

(b) Reading part by I.L.O. classification and part by the N.C.B. elaboration.

(c) Reading into the N.C.B. elaboration. 
pattern for individual readers. Thus there was no indication of changed levels of reading.

Further light may be cast on this question by Table 7, which gives the distributions of prevalence, reader by reader, in trials 5 and 6 , using (1) the I.L.O. classification alone, and (2) the N.C.B. elaboration but taking no account of the alternates. The 'average' category is also given. From Table 7(a), the 'average' category is seen to be similar, for most readers in trial 5 , by both methods of classification; there was more variation between readers using the same classification. From Table 7(b), it can be seen that in trial 6 the agreement in 'average' category was even closer than in trial 5 , and the variation between readers rather greater.

Consistency of reading levels over a period of time In Table 8, material is presented from the three checks on the consistency of reading for P.X.R. purposes, in which films from one check were read on the next check. The variation between checks in the 'average' category was very small in each trial despite the different methods of reading.

Effects on observer error As explained in Appendix III, the best measure of observer error, taking into account both sensitivity and consistency, is considered to be the average amount of information transmitted. This statistic has been calculated for both those trials (i.e., trials 2 and 5) in which a reader assessed batches of films twice by both the I.L.O. classification and the N.C.B. elaboration. Table 9 is thus a summary of all the evidence available on the effect of the elaboration on intra-observer error. For trial 2, the average information transmitted on the same films when read by either method (but when

\section{TABLE 9}

INTRA-OBSERVER ERROR: AMOUNTS OF INFORMATION TRANSMITTED BY THE SAME READER ON TWO OCCASIONS Trials 2 and 5.P.X.R. readers

\begin{tabular}{c|c|c||c|c}
\hline & \multicolumn{2}{|c||}{ Trial 2 } & \multicolumn{2}{c}{ Trial 5 } \\
\cline { 2 - 5 } Reader & $\begin{array}{c}\text { I.L.O. } \\
\text { classifica- } \\
\text { tion }\end{array}$ & $\begin{array}{c}\text { N.C.B. } \\
\text { elabora- } \\
\text { tion }\end{array}$ & $\begin{array}{c}\text { I.L.O. } \\
\text { classifica- } \\
\text { tion }\end{array}$ & $\begin{array}{c}\text { N.C.B. } \\
\text { elabora- } \\
\text { tion }\end{array}$ \\
\hline X.1 & 1.11 & 2.39 & 0.83 & 1.53 \\
X.2 & 0.98 & 2.26 & 0.75 & 1.57 \\
X.3 & 1.00 & 1.87 & 0.85 & 1.41 \\
X.4 & 1.07 & 1.75 & 0.89 & 1.60 \\
Y.2 & 0.99 & 1.39 & - & - \\
Y.3 & 1.12 & 1.52 & - & -1.45 \\
Y.4 & 0.82 & 1.20 & 0.70 & 1.51 \\
\hline Average & 1.01 & 1.77 & 0.80 & 1.51 \\
\hline
\end{tabular}

alternates were ignored in the analysis of the readings in the elaboration) was almost identical, as has been seen from Table 6 . But substantially more information was transmitted in a closely similar batch of films in which full use was made of the elaboration, i.e., 1.77 compared with 1.01 and 1.05 . Even those readers (Y.2 and Y.3) who made little use of the marginal zones gained considerably from such use as they did make of them. A closely similar finding arose in trial 5 , where the transmitted information was nearly twice as great in the elaboration as in the unelaborated classification ( 1.51 compared with 0.80$)$. (It is of interest that in this trial the P.F.R. readers, using only the I.L.O. classification, also transmitted almost exactly the same amount of information on average $(0 \cdot 79)$.) It should be emphasized that the improvements ascribable to the use of the elaboration are consistent for all readers.

Inter-observer error is correspondingly summarized in Table 10, based on trials 2, 5, and 6 .

\section{TABLE 10}

INTER-OBSERVER ERROR: AMOUNTS OF INFORMATION TRANSMITTED BY ONE READER COMPARED WITH THE AVERAGE READING

Trials 2, 5, and 6. P.X.R. and P.F.R. readers

\begin{tabular}{|c|c|c|c|c|}
\hline \multirow{2}{*}{$\begin{array}{l}P . X . R . \\
\text { readers }\end{array}$} & \multicolumn{2}{|c|}{ Trial 2} & \multicolumn{2}{|c|}{ Trial 5} \\
\hline & $\begin{array}{l}\text { I.L.O. } \\
\text { classifica- } \\
\quad \text { tion }\end{array}$ & $\begin{array}{c}\text { N.C.B. } \\
\text { elabora- } \\
\text { tion }\end{array}$ & $\begin{array}{l}\text { I.L.O. } \\
\text { classifica- } \\
\quad \text { tion }\end{array}$ & $\begin{array}{c}\text { N.C.B. } \\
\text { elabora- } \\
\text { tion }\end{array}$ \\
\hline $\begin{array}{l}\text { X.1 } \\
\text { X.2 } \\
\text { X.3 } \\
\text { X.4 } \\
\text { Y.2 } \\
\text { Y.3 } \\
\text { Y.4 }\end{array}$ & $\begin{array}{l}0.84 \\
0.82 \\
1.02 \\
0.78 \\
0.92 \\
0.62 \\
0.39\end{array}$ & $\begin{array}{l}1.49 \\
1.51 \\
1.53 \\
1.51 \\
1.45 \\
1.13 \\
1.25\end{array}$ & $\begin{array}{r}0.96 \\
0.70 \\
0.91 \\
0.97 \\
- \\
0.90\end{array}$ & $\begin{array}{r}1.69 \\
1.64 \\
1.73 \\
1.85 \\
= \\
1.61\end{array}$ \\
\hline Average & 0.77 & 1.41 & 0.89 & $1 \cdot 71$ \\
\hline & \multirow{2}{*}{$\begin{array}{l}\text { P.F.R. } \\
\text { readers }\end{array}$} & \multicolumn{2}{|c|}{ Trial 6} & \\
\hline & & $\begin{array}{c}\text { I.L.O. } \\
\text { classification }\end{array}$ & \multicolumn{2}{|l|}{$\begin{array}{c}\text { N.C.B. } \\
\text { elaboration }\end{array}$} \\
\hline & $\begin{array}{l}\text { F.1 } \\
\text { F.2 } \\
\text { F.3 } \\
\text { F.4 }\end{array}$ & $\begin{array}{l}1.28 \\
0.98 \\
1.34 \\
1.14\end{array}$ & $\begin{array}{l}2 \cdot 16 \\
1.99 \\
2 \cdot 42 \\
2 \cdot 19\end{array}$ & \\
\hline & erage & $1 \cdot 18$ & $2 \cdot 19$ & \\
\hline
\end{tabular}

Once again the improvement, within each trial, due to the use of the elaboration is clear; it, too, was consistent from reader to reader. (As before, 
TABLE 11

INTER-ObSERVER ERror: Percentages of READINGS BY ONE OBSERVER AGREEING AND DISAGREEING WITH THE AVERAGE READING Trial 6. Four P.F.R. readers

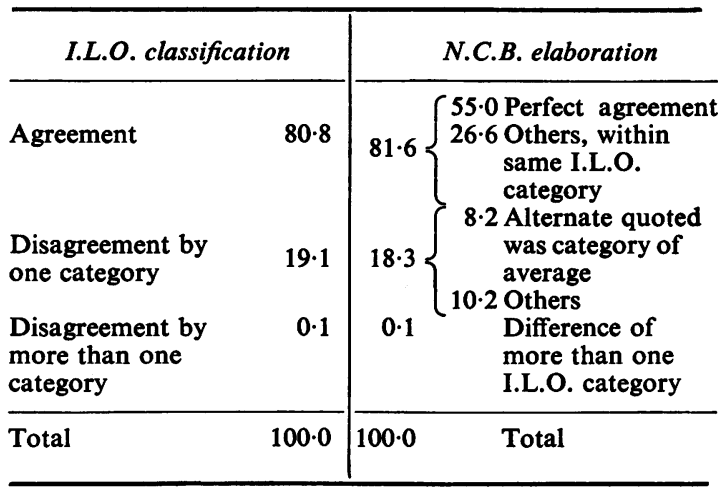

P.X.R. and P.F.R. readers using the same (I.L.O.) classification on the same films had almost identical levels of error.)

It is perhaps instructive to look at inter-observer error another way, as in Table 11 relating to trial 6. This shows that when alternates are ignored, the proportions of agreements and disagreements are almost identical in I.L.O. classification and N.C.B. elaboration: this finding was repeated exactly for all four readers. Further, in nearly two thirds of the cases where a reader agreed the I.L.O. category of the average reader, he agreed perfectly in the elaboration $(55.0 \%$ compared with $81.6 \%)$. Again, in nearly half the cases where he disagreed the I.L.O. category of the average, he had nevertheless seriously considered it as an alternate $(8.2 \%$ compared with $18 \cdot 3 \%$ ).

Effect of radiographic technique on improvement of observer error An attempt has been made to study

TABLE 12

Film Quality AND ObSERVER ERror: AMOUNT OF INFORMATION TRANSMITTED Trial 2. Seven P.X.R. readers

\begin{tabular}{l|c|c}
\hline & $\begin{array}{c}\text { I.L.O. } \\
\text { classification }\end{array}$ & $\begin{array}{c}\text { N.C.B. } \\
\text { elaboration }\end{array}$ \\
\hline $\begin{array}{c}\text { Intra-observer error } \\
\text { 'Good' films }\end{array}$ & $\begin{array}{l}1.02 \\
1.14\end{array}$ & $\begin{array}{c}1.50 \\
1.89\end{array}$ \\
\hline Bad' films & $\begin{array}{l}\text { Inter-observer error } \\
\text { 'Good' films } \\
\text { 'Bad' films }\end{array}$ & $\begin{array}{l}1.80 \\
0.90\end{array}$ \\
\hline
\end{tabular}

this problem using data from trial 2. It is made particularly difficult because of the marked difference in the distribution of pneumoconiosis among 'good' and 'bad' films; the 'good' films contained a very much higher proportion of normals, and particularly of $0 /$ - readings. However, Table 12 shows that both intra-observer and inter-observer error were markedly better on average, on both 'good' and 'bad' films, when the elaboration was used rather than the I.L.O. classification $(1.50$ compared with 1.02 , etc.). This finding was repeated for all seven P.X.R. readers, even including Y.2 and Y.3. (No comparison can be made between the levels of information on 'good' and on 'bad' films because of the very great effect of the distribution of abnormality on the value of the statistic.)

Differentiation of marginal zones This subject is examined on the material from trial 2 for the five readers who made consistent use of the marginal zones and where film quality could be taken into account. Table 13 summarizes the effects of ignoring the differentiation of marginal zones. Row (a) shows that to

TABLE 13

EFFECTS OF IGNORING DiFFERENTIATION OF Marginal Zones: Average AMOUNTS OF INFORMATION TRANSMITTED Trial 2. Five P.X.R. readers

\begin{tabular}{|c|c|c|c|c|}
\hline & \multicolumn{2}{|c|}{$\begin{array}{c}\text { Intra-observer } \\
\text { error }\end{array}$} & \multicolumn{2}{|c|}{$\begin{array}{c}\text { Inter-observer } \\
\text { error }\end{array}$} \\
\hline & $\begin{array}{l}\text { 'Good' } \\
\text { films }\end{array}$ & $\begin{array}{l}\text { 'Bad' } \\
\text { films }\end{array}$ & $\begin{array}{l}\text { 'Good' } \\
\text { films }\end{array}$ & $\begin{array}{l}\text { 'Bad' } \\
\text { films }\end{array}$ \\
\hline All 12 zones differentiated & 1.63 & $1 \cdot 97$ & $1 \cdot 51$ & 1.57 \\
\hline $\begin{array}{l}\text { Treating as identical: } \\
\text { (a) } 0 /-=0 / 0 \\
\text { (b) } 0 / 1=1 / 0 ; 1 / 2=2 / 1 ; \\
2 / 3=3 / 2 \quad . \quad \\
\text { (c) } 0 /-=0 / 0 ; 0 / 1=1 / 0 ; \\
1 / 2=2 / 1 ; 2 / 3=3 / 2 ; \\
3 / 3=3 / 4 \quad \ldots \quad .\end{array}$ & $\begin{array}{r}1.28 \\
1.55\end{array}$ & $\begin{array}{l}1.86 \\
1.56\end{array}$ & $\begin{array}{l}1 \cdot 27 \\
1 \cdot 38\end{array}$ & $\begin{array}{l}1.48 \\
1.35\end{array}$ \\
\hline
\end{tabular}

treat $0 /-$ as indistinguishable from $0 / 0$ reduces the amount of information transmitted by about $12 \%$ on average; and row (b) shows that to treat adjacent marginal zones as indistinguishable leads to a similar reduction. These two effects combined, together with treating $3 / 4$ as equivalent to $3 / 3$ (row (c) ), lead to a reduction of about $25 \%$. These reductions vary according to film quality (and from reader to reader) only as much as would be expected by the variation in the use of the zones. Thus it appears beneficial to distinguish all the zones as used. 
It is also worth comment that the $0 /$-zone appears to be distinguishable, better than the others. Thus, it is virtually unknown for a reader who had assessed a film on any one occasion to read it higher than $0 / 0$ on another occasion, and it is very rare for a second reader to do so.

\section{Discussion}

It is clear that individual readers do not place closely similar proportions of films into the various zones of the N.C.B. elaboration. This is not unexpected in view of the definitions: they depend on the terms 'serious possibility' and 'no doubt'. Without any briefing, these terms are obviously open to wide variation in interpretation. However, with adequate briefing it is possible to get a reasonable degree of consistency in a group of readers. There is, however, a little evidence (from Tables 2 and 3) that the use of marginal zones decreased over time. In addition, it is clear that within I.L.O. category 0 , in which most films from natural populations are placed, the use of the zones is strongly influenced by film quality.

This lack of consistency might, at first sight, appear a drawback of fundamental importance. However, this is not so. Although the additional information obtained by use of the elaboration is not exactly the same for each reader, it is nevertheless additional. Thus, statements on the prevalence of pneumoconiosis can be made with confidence in terms of the I.L.O. classification, simply by ignoring the alternates, while the use of the alternates themselves clearly leads to marked improvements in observer error; and these improvements occur irrespective of film quality.

The evidence we have presented leads us to conclude that the 12 zones of the elaboration can be considered as showing steadily increasing radiological abnormality. This is not to say that the differences between adjacent zones are necessarily due solely to differences in dust retention. In particular, the $0 / 0$ film may differ from the $0 /-$ not so much because of development of early pneumoconiosis but because of non-specific radiological change due to, say, the presence of bronchitis or to ageing (perhaps associated with exposure to atmospheric pollution), or even arising out of imperfect radiographic technique. Nor does this evidence allow us to be sure into what proportions the zones split each I.L.O. category. This is beyond the scope of the present paper, but two trials have been conducted recently to examine this subject, and preliminary findings provide strong support for our conclusion that the zones show steadily increasing abnormality.

We must also consider whether any alternative classification would be more advantageous. The 4-point scale of the I.L.O. classification is too coarse when considered from a statistical viewpoint, particularly when it is borne in mind that the radiographs of the vast majority of miners are placed in I.L.O. category 0; in British mines, P.X.R. placed $88 \%$ of nearly 463,000 men into this category (Rogan, 1964). The need for refinement has been clear to many workers ${ }^{1}$ for a long time. One approach is to introduce 'half-categories', and some success has been achieved by other workers. However, this leads only to a 7-point scale and the evidence now is that the finer the scale (within reason) the better. It might nevertheless be thought worth treating adjacent marginal zones as identical, e.g., treating $0 / 1$ and $1 / 0$ as having the same meaning, in order to make the resulting zones roughly equal in frequency of use. On the other hand, the scale would be reduced to 9-point, and it has been demonstrated that transmitted information would be correspondingly less. Further, it would mean that the borderlines of the I.L.O. categories would fall within, and not on the edges of, the resulting zones, leading to potential difficulties in such matters as comparing statements on prevalence.

Thus, of all the refinements that have been tried, the N.C.B. elaboration appears the most suitable. It achieves the important object of increasing information without distorting in any way the basic categorization. Further, it seems probable that, if it were desired to make statements on prevalence in terms of the 12-point scale in detail, readers could conform to a consistent pattern of use of the zones with adequate briefing and experience. Meanwhile, it is clear that the elaboration can be used successfully, for the purpose of increasing information, without training; it avoids the need for any more specific definitions of category boundaries.

There are two further very considerable advantages of the elaboration. First, it makes important contributions in the assessment of the radiological progression of pneumoconiosis. Full details are given by Liddell and May (1966) and by Liddell (1969). It is obviously desirable to use the same refinement for reading single films as for reading pairs. The second advantage is the considerable improvement in ease of reading, as reported by Gilson (1967), among others.

Finally, comment should be made on the possibility of achieving a similar degree of increased sensitivity by some form of multiple reading using the unelaborated I.L.O. classification. Undoubtedly this is possible: but it is inefficient in the use of skilled reading ability. To obtain a 12-point scale

\footnotetext{
1Blair et al. (1966), however, make the judgement that any proposed category additional to the I.L.O. classification would be acceptable only if reproducibility were maintained. By ignoring potential improvement in sensitivity, this view begs the fundamental question of how to find the best balance of consistency and sensitivity. See also Appendix III.
} 
by a single reading into the N.C.B. elaboration appears better than to achieve a scale of similar fineness involving three or four times the reading effort. Multiple reading does, of course, allow to some extent for diurnal variations in reading levels, and if the effort can be made available it should be used with the elaboration to obtain much greater sensitivity still. This would be a most attractive possibility if (as has been suggested over the years) the process of film reading for research purposes can just as well be carried out by lay readers as by those medically qualified, and particularly should it prove possible to select people who are especially good in the use of such a classification.

The authors wish to acknowledge their great debt to Dr. J. A. Dick, Dr. R. R. Dodd, Dr. J. C. Griffiths, Dr. J. B. Menzies, Dr. D. C. Morgan, Dr. L. J. G. Morgan, Dr. W. H. Oldershaw, Dr. R. H. S. Pasqual, Dr. N. G. Pearson, Dr. S. Rae, and Dr. J. S. Washington, who participated in the film reading and who have provided helpful advice. They are also indebted to Dr. J. C. Gilson, Dr. J. S. McLintock, and Mr. P. D. Oldham for valuable criticism and help. They thank Miss E. D. Mead and the staff of Medical Statistics Branch for the large amounts of data processing and statistical analysis. They are very grateful to Dr. J. M. Rogan, Chief Medical Officer, for his encouragement and for permission to publish this paper. The views expressed in it are, however, their own responsibility.

\section{References}

Ashford, J. R., and Enterline, P. E. (1966). The classification of chest radiographs for pneumoconiosis. In Blair et al. (1966). Arch. environm. Hlth., 12, 327-330.

Blair, L. G., Cochrane, A. L., Dick, J. A., McCallum, R. I., Rae, S. Rogan, J. M., Felson, B., Flinn, R. H., Jacobson, G., Milby, T. H. Jr., Pendergrass, E. P., Ashford, J. R., and Enterline, P. E. (1966). Radiologic classification of the pneumoconioses. Ibid., 12, 314-330.

Fay, J. W. J., and Rae, S. (1959). The Pneumoconiosis Field Research of the National Coal Board. Ann. occup. Hyg., 1, 149-161.

Gilson, J. C. (1967). Personal communication.

International Labour Office (1959). Meeting of experts on the international classification of radiographs of the pneumoconioses 1958 . In Occup. Safety \& Hlth, 9, 63-69, Geneva.

Kullback, S. (1959). Information Theory and Statistics. Wiley, New York.

Liddell, F. D. K. (1961). The effect of film quality on reading radiographs of simple pneumoconiosis in a trial of $X$-ray sets. Brit. $J$. industr. Med., 18, 165-174.

(1963). An experiment in film reading. Brit.J. industr. Med., 20, 300-312.

(1969). Methods of assessing radiological progression of simple pneumoconiosis. In preparation.

, and May, Joan D. (1966). Assessing the Radiological Progression of Simple Pneumoconiosis. Medical Research Memorandum 4. National Coal Board, London.

Rogan, J. M. (1964). Medical Service and Medical Research: Annual Report 1963. National Coal Board, London.

\section{Appendix I}

Terminology

I.L.O. classification The conventional (unelaborated) International Labour Office (1959) classification of pneumoconiosis
N.C.B. elaboration The elaboration described in this paper and illustrated in the Figure

I.L.O. category A category $(0,1,2$, or 3$)$ of the I.L.O. classification

Alternate The I.L.O. category, adjacent to that first recorded, considered as a serious possibility, e.g., in the reading $2 / 1$, the alternate is category 1

Central zone That (central) part of each I.L.O. category where a reader, using the N.C.B. elaboration, has not recorded an alternate. The central zones are $0 / 0,1 / 1,2 / 2$, and $3 / 3$

Marginal zones The other (i.e., non-central) zones of each I.L.O. category. The marginal zones are $0 /-, 0 / 1,1 / 0$, $1 / 2,2 / 1,2 / 3,3 / 2$, and $3 / 4$

P.F.R. The National Coal Board's Pneumoconiosis Field Research (Fay and Rae, 1959)

P.F.R. readers The film readers of P.F.R.; they are identified as F.1 to F.4

P.X.R. The National Coal Board's Periodic $X$-ray Scheme (Rogan, 1964).

P.X.R. readers The film readers of P.X.R.: those who took part in all relevant trials are identified as X.1 to X.4; those who were only available for certain trials as Y.1 to Y.4

For notes on amount of information transmitted, see Appendix III.

\section{Appendix II \\ Details of trials}

Trial 1 (3rd check on the consistency of film reading in P.X.R.)

A total of 350 single films was included. They had all been taken in the course of routine P.X.R. surveys, in all coalfields. Most of the films came from surveys in 1960 , but over 50 had been taken in 1959 and had been incorporated into the previous (2nd) check.

The films were selected, at Headquarters, in terms of the original (survey) readings of the films to give equal numbers from each $x$-ray Unit, and to give high (and roughly equal) proportions of abnormality; in particular there were very few normal films and a very high proportion of those which had been placed in I.L.O. category 1 on survey.

The I.L.O. classification was used throughout.

Each P.X.R. reader in post assessed each film once only. The readers concerned were $X .1$ to $X .4$ and $Y .1$ to Y.3.

Trial 2 (4th check on the consistency of film reading in P.X.R.)

A total of 350 single films was included, selection being very much as for the 3rd check except that $(a)$ the majority of the films had been taken in 1961, with nearly 50 from the 3rd check (trial 1), and (b) the pattern of abnormality was rather more realistic although still at a higher level than natural. 
The films were put into seven batches, which were designed (and proved) to be as nearly identical as possible. Each reader read three of the batches twice. For one of these batches, he used the I.L.O. classification on both occasions; for a second, he used the N.C.B. elaboration on both occasions; for the third, he used the I.L.O. classification on one occasion and the elaboration on the other occasion. Each reader read two more batches, once only, using the I.L.O. classification; he read the two final batches, once only, using the N.C.B. elaboration.

All P.X.R. readers in post took part. They were X.1 to X.4 and Y.2 to Y.4.

Trial 3 (5th check on the consistency of film reading in P.X.R.)

A total of 350 films was included, selected as before except that $(a)$ the majority of the films had been taken in 1962, with over 60 coming from the 4th check (trial 2), and $(b)$ the pattern of abnormality in the sample was made more realistic still.

The N.C.B. elaboration was used throughout.

Each P.X.R. reader in post assessed each film once only. The readers concerned were $X .1$ to $X .4$ and $Y .3$ and Y.4.

Trial 4 (Preliminary P.X.R. enquiry into methods of assessing progression)

A total of 300 films was included. They consisted of pairs of films for 150 subjects $x$-rayed within P.F.R. The films were selected from four collieries, and from a very much earlier trial, to make an appropriate sample for the purposes of the enquiry. The distribution of abnormality in the complete series, treated as single films, was fairly similar to that of trial 3 (see Liddell and May, 1966, p. 48). The films were placed into three batches which were shown to be virtually identical. They were assessed singly (inter alia) in a quasi-random order with the pair of films for a subject separated sufficiently for it to be clear that the reader could have no knowledge of one film when assessing its pair.

The N.C.B. elaboration was used throughout.

Each P.X.R. reader in post assessed one batch twice and a second batch on one occasion. (The third batch was not read in this way by the same reader, because of a complex trial design which had to meet specific purposes, while minimizing effects of learning, etc.) The readers who took part were X.1 to X.4 and Y.2 to Y.4.

Trial 5 (Main P.X.R. investigation of methods of assessing progression)

A total of 378 films was included. Selection was similar to that for trial 4, except that films came also from P.X.R. sources. The distribution of abnormality was reasonably close to that of trial 3 (see Liddell and May (1966, p. 49)).

Each P.X.R. reader in post assessed each single film on four separate occasions, twice into the I.L.O. classification and twice into the N.C.B. elaboration. The readers were X.1 to X.4 and Y.4. P.F.R. readers also took part, but only using the I.L.O. classification.

Trial 6 (P.F.R. trial 65X1)

A total of 314 films was included. They were those read for trial 5 with certain exclusions forced by clinical considerations.

Each P.F.R. reader (F.1 to F.4) read each single film on two separate occasions, once into the I.L.O. classification and once into the N.C.B. elaboration.

Trial 7 (P.F.R. trial 66X1)

A total of 600 films was included. Selection was of three serial films for 200 subjects at three P.F.R. collieries. The subjects were chosen to give as even as possible a spread of their measured dust exposures, and the distribution of abnormality in the series treated as single films was reasonably 'natural'.

The N.C.B. elaboration was used throughout.

Each P.F.R. reader (F.1 to F.4) assessed each single film on two separate occasions.

\section{Appendix III}

\section{Measurement of observer error}

Observer error in reading a chest radiograph for simple pneumoconiosis (as in all diagnostic procedures) must be assessed in terms of both sensitivity and consistency, which are related but conflicting aims. To do so is comparatively easy where measurement has been made on a cardinal scale with many steps (as in most measurements in the physical sciences, e.g., of height, weight, and time). It is then possible to determine by straightforward statistical techniques the standard deviation of an observation, and this can be used to define confidence limits, which in turn indicate the degree of sensitivity.

But, until more work has been done on validation, it cannot be assumed that any scale of simple pneumoconiosis is truly cardinal (although it is not unreasonable to assume it is ordinal); and even the N.C.B. elaboration consists of only 12 steps. There is a further complication which becomes of importance in this situation: in virtually all working populations the distribution of abnormality is highly skew; in other words, there is a high proportion of films with normal appearances while the comparatively few remaining films have to be classified into yet smaller groups according to the severity of the condition. No measure of observer error is known which is satisfactory in all these circumstances.

It is considered that the least unsatisfactory is the average amount of information transmitted. The method of calculation is given in the Appendix to Liddell (1963), together with a convenient table. This statistic has certain close affinities to the $\chi^{2}$ statistic commonly used for the analysis of two-way tables. Both take consistency and sensitivity into account together, but $\chi^{2}$ is much more difficult to calculate. The theoretical background of information statistics is given in a standard text by Kullback (1959). A heuristic justification is in Liddell (1963).

The upper limit of the amount of information transmitted is determined in any particular situation by the number of categories in the classification being used and by the distribution of abnormality in the series of films being examined. In a selected series in which the numbers of films in the various categories are closely similar, the statistic could approach the theoretical limit which is $\log _{2}$ (number of categories), or 2.00 binary digits for the I.L.O. classification, 3.58 for the N.C.B. elaboration. 
But in a 'natural' series, where there is a heavy preponderance of films with normal appearances, the maximum information which could be transmitted will be very much less: the more uneven the distribution over the categories the lower the practical limit on the statistic.

It is important to appreciate that the increased information transmitted with the N.C.B. elaboration is not simply an artefact of the finer scale: it arises because of the tendencies $(a)$ towards perfect agreement even within the finer classification, and $(b)$ in those cases where the I.L.O. category is not agreed, for that category nevertheless to be quoted as alternate; see Table 11 for an illustration of these tendencies, which have been found to arise in all applications. Thus, the amount of information transmitted can be used for comparisons between classifications used in any one trial. On the other hand, the dependence of the value of the statistic on the distribution of abnormality means that comparisons cannot be made of results from different trials unless the distributions of abnormality in the trials concerned were similar.

Reproducibility, as defined by Ashford and Enterline (1966), both for a classification and for a category, are reasonably satisfactory for certain comparisons of readers' performance, e.g., on a single set of films. However, these measures are in no way concerned with sensitivity. They also, of course, depend on the distribution of abnormality. This is recognized by Ashford and Enterline's colleagues (Blair et al., 1966) when they propose a 'standard of reproducibility' in terms of a population containing a specific percentage of abnormal films. (They do not make recommendations on what is acceptable when the proportion of abnormal films is different.) However, although these workers express the view that reproducibility must be maintained, they ignore potential improvements in sensitivity, and make no attempt to examine the balance of consistency with sensitivity.

Received for publication July 18, 1968. 